\title{
Gude: a produtividade das variantes lexicais dos grupos ciganos e não- ciganos da Bahia e de Pernambuco
}

\section{Marble: the productivity of the lexical variants of the gypsies and non-gypsies groups from Bahia and Pernambuco}

\author{
Geysa Andrade da Silva ${ }^{1}$ \\ Silvana Soares Costa Ribeiro ${ }^{2}$
}

Resumo: Essa pesquisa analisa respostas fornecidas por falantes de etnia cigana, dos estados da Bahia e de Pernambuco, em Silva (2017) no que se referente às designações para "bolinha de gude", comparando-as com as fornecidas por falantes não-ciganos estudados por Ribeiro (2012). O objetivo é examinar se na seleção lexical feita pelos entrevistados há influência de fatores diatópicos, diassexuais e diageracionais identificados a partir dos dados recolhidos. Tais análises permitiram observar, dentre outros aspectos, a produtividade das variantes identificadas nos trabalhos e a variação diatópica constatada. Consideraram-se os pressupostos e a metodologia da Sociolinguística e da Dialetologia Pluridimensional bem como da Lexicologia e da Ciganologia. As considerações finais descrevem e abordam os resultados obtidos. Em síntese, o estudo confirmou que o brinquedo "bolinha de gude" cultiva-se nos dois estados pesquisados, conforme atestam as escolhas lexicais dos falantes, que tanto no grupo cigano quanto no grupo não-cigano foram semelhantes. O conhecimento das variantes léxico-regionais apuradas e sua dispersão pela área geográfica revelaram que: (i) na pesquisa de Silva (2107), a lexia de maior frequência, na Bahia, é gude e, em Pernambuco, é bila, ambas com $100 \%$ das respostas válidas; (ii) na pesquisa de Ribeiro (2012), tem-se $96,70 \%$ de gude, na Bahia, e $43,75 \%$ de bila, na rede de pontos de Pernambuco.

Palavras-chave: Dialetologia; Léxico; Gude; Português do Brasil; Ciganos e não-ciganos.

Abstract: This research analyzes responses provided by gypsy speakers from the states of Bahia and Pernambuco in Silva (2017) regarding the designations for "marbles", comparing them with those provided by non-gypsy speakers studied by Ribeiro (2012). The objective is to examine whether in the lexical selection made by the interviewees there is influence of diatopic, diassexual and diagerational factors identified from the collected data. These analyzes allowed to observe, among other aspects, the productivity of the variants identified in the works and the diatopic variation verified. The assumptions and methodology of Sociolinguistics and Pluridimensional Dialectology as well as Lexicology and Gypsy studies were considered. The final considerations describe and address the results obtained. In summary, the study confirmed that the toy "marbles" is cultivated in the two states surveyed, according to the lexical choices of the speakers,

\footnotetext{
${ }^{1}$ Docente na Universidade do Estado da Bahia, CAMPUS IV - Jacobina; doutoranda no Programa de Pós-Graduação em Língua e Cultura da Universidade Federal da Bahia; geysasilva@uneb.br.

2 Docente no Programa de Pós-Graduação em Língua e Cultura do Instituto de Letras da Universidade Federal da Bahia - UFBA; silvanar@ufba.br.
} 
that in both the gypsy group and the non-gypsy group were similar. The knowledge of lexical-regional variants and their dispersion in the geographical area revealed that: (i) in Silva's research (2017), the most frequent word in Bahia is gude, and in Pernambuco it is bila, both with $100 \%$ of valid answers; (ii) in Ribeiro's survey (2012), there is $96.70 \%$ of gude in Bahia and $43.75 \%$ in the network of points of Pernambuco.

Keywords: Dialectology; Lexicon; Marbles; Portuguese of Brazil; Gypsies and non-Gypsies.

\section{Introdução}

O texto objetiva apresentar os resultados alcançados a partir da pesquisa que se fundamenta na Lexicologia e faz uma interface entre Sociolinguística e Dialetologia, com destaque para lexias usadas pelos informantes de comunidades ciganas e não-ciganas da Bahia e de Pernambuco, a partir da comparação da pesquisa de Silva (2017) e de Ribeiro (2012). O estudo foi motivado pela análise da questão 156 do Questionário Semântico-lexical - doravante QSL - do Projeto Atlas Linguístico do Brasil ALiB, com base na área semântica de jogos e diversões infantis, que fornece dados que marcam a variação lexical do povo cigano. A pergunta estudada do QSL vem assim descrita "Como se chama as coisinhas de vidro que os meninos usam para brincar? (COMITÊ NACIONAL..., 2001, p.34).

Vale-se dos pressupostos teóricos apresentados por Souza Santos (2000), Oliveira; Isquerdo (2001), Hall (2006), Labov ([1972] 2008), Cardoso (2010), Nunes (2010), Antunes (2012), Ribeiro (2012) e Callou (2012).

O léxico referente a jogos e brincadeiras infantis é muito rico e diversificado e pouco difundido, como afirma Ribeiro (2012), por isso mesmo, constitui-se uma área de estudo instigante.

\section{Léxico: negociação}

A língua está homogênea somente na gramática e nos dicionários pressupondo um falante ideal e, portanto, artificial, mas é no convívio social que a língua é apreendida pelos seus falantes e tem compreensão eficiente entre os interlocutores, apesar de toda sua heterogeneidade.

Este convívio social é também responsável pela dinamicidade do léxico da língua, uma vez que sua flexibilidade se adapta às necessidades dos falantes. Considere aqui as questões geográficas, de sexo, faixa etária, grau de escolaridade, nível de formalismo da conversa, entre tantos outros fatores sociais que podem influenciar as escolhas dos usuários da língua. A seleção de determinados itens do léxico em detrimento de outros do eixo paradigmático, traz consigo toda a carga semântica projetada nessa alternativa. Tal ação só é possível dadas as possibilidades de combinações dentro da língua viva dos falantes.

Ribeiro (2012, p.107) amplia essa visão de mudança de sentido de elementos que compõem o léxico de uma língua, associando-a ao coletivo e, portanto, à comunidade linguística, quando revela que 
lento e constante de mudança de sentido das palavras que são efetivamente usadas pelos falantes. Quando um novo sentido é assimilado pela coletividade e se generaliza, aquela palavra amplia seu campo de significação, tornando-se polissêmica. (RIBEIRO, 2012, p.107).

Quando se admite que os signos linguísticos são rótulos que permitem ao homem interagir cognitivamente com seu meio, que as línguas naturais possuem uma riqueza cultural abstrata e que 0 léxico representa um patrimônio imaterial de uma dada comunidade linguística, reconhece-se uma zona de troca entre língua e mundo, léxico e sociedade.

O léxico pode indicar, assim, a busca de pertencimento. Torna-se uma possibilidade entre os fenômenos identitários que produzem efeitos pela e na língua. Muitas são as faces do léxico e da identidade, fruto de inúmeras reflexões e visualizados por vários ângulos; no entanto, alguns estudiosos e suas questões norteiam nossos olhares.

As sociedades globalizadas vivem mudanças constantes, rápidas e permanentes, segundo Hall (2006), e isso causa um alto impacto sobre as identidades; sociedades constantemente deslocadas desarticulam as identidades estáveis do passado, ao mesmo tempo em que surgem novas possibilidades de articulações. Souza Santos (2000) fez referência a esse mesmo pensamento:

\begin{abstract}
Sabemos hoje que as identidades culturais não são rígidas nem, muito menos, imutáveis. São resultados sempre transitórios e fugazes de processos de identificação. Mesmo as identidades aparentemente mais sólidas, como a de mulher, homem, país africano, país latino-americano ou país europeu, escondem negociações de sentido, jogos de polissemia, choques de temporalidades em constante processo de transformação, responsáveis em última instância pela sucessão de configurações hermenêuticas que de época para época dão corpo e vida a tais identidades. Identidades são, pois, identificações em curso (SOUZA SANTOS, 2000, p.135).
\end{abstract}

O léxico é marca desta identidade. Os valores, crenças, costumes, comportamento social, diversões de uma comunidade, entre tantos outros itens, manifestam-se a partir do léxico, ele

[...] representa a janela através da qual uma comunidade pode ver o mundo, uma vez que esse nível da língua é o que mais deixa transparecer os valores, as crenças, os hábitos e os costumes de uma comunidade, como também, as inovações tecnológicas, transformações socioeconômicas e políticas ocorridas em uma sociedade. (OLIVEIRA; ISQUERDO, 2001. p.9).

A forma como a comunidade se organiza é fruto da consciência lexical dos seus membros, que assim deixam transparecer uma relação direta entre léxico e cultura. O patrimônio vocabular de uma comunidade linguística é, portanto, uma riqueza cultural imaterial.

Apesar de toda renovação, o léxico não é destituído de toda e qualquer estabilidade de significado, criando-se sentidos a partir do zero, mas é um sistema "aberto, inesgotável, constantemente renovável, não apenas porque surgem novas palavras, mas também pela dinâmica interna das palavras, que vão e vêm, que desaparecem e reaparecem, que mantêm seus significados ou os mudam, de um lugar para o outro, de um tempo para o outro" (ANTUNES, 2012, p. 29). 


\section{$\mathbf{O}$ aporte das ciências}

As ciências da linguagem são numerosas, não se restringem a todas as Linguísticas (geral, aplicada, descritiva, etc) que se debruçam sobre o estudo da língua, junte-se a elas uma rede de tantas outras abordagens como a Estilística, Análise do discurso, Lexicografia, Lexicologia, Sociolinguística, Dialetologia, Filologia, Terminologia e mais um punhado de outras.

Um dos progressos da Linguística moderna está em tentar unir ou aproximar o estudo das línguas, pondo um olhar especial sobre o fato de que a língua é coletiva e, portanto, social; uma herança cultural, revestida de contribuições individuais. No entanto, tais ciências irão abordar a linguagem de uma maneira distinta, cada uma ao seu modo, lançando mão do seu método.

No mundo contemporâneo, é preciso que o homem amplie seu repertório lexical para dar conta de objetos, seres, de sentimentos, de lugares, de ações, estando assim o léxico mergulhado num processo de expansão permanente. Por outro lado, a leitura e a cultura impedem que itens lexicais vigentes em gerações passadas caiam completamente em desuso ou até desapareçam por falta de quem as utilize.

Lexicologia é o ramo da linguística contemporânea que estuda o léxico, Nunes (2010, p.149) caracterizando a ciência revela que "a lexicologia identifica e descreve as unidades lexicais [...][e que] o estudo do léxico tende para um saber especulativo", assim sendo, leve-se em consideração a possibilidade de sentidos diferentes para a mesma palavra, a depender das posições sustentadas pelos sujeitos e o valor na relação com os outros.

Hoje, é uma ciência de limites tênues como tantas outras, isso porque precisa considerar uma série de dimensões baseadas no léxico, ora para descrevê-lo, ora para significá-lo, ora para especificá-lo em uma área do conhecimento humano, ora para territorializá-lo, etc. Assim, as aportes das ciências costumam ser sempre parciais.

Outras ciências, portanto, dialogam neste espaço. A lexicologia concebe suporte para os estudos lexicais - no ponto em que ela se faz interdisciplinar com a Dialetologia, por exemplo. A Sociolinguística, também utilizada como suporte para o trabalho, é uma das ciências que investiga a correlação de fatores como idade, sexo, escolaridade, classe social, nível de renda, profissão, religião, etnia e outras características circunstanciais que envolvem o falante ou o evento da fala e ainda os fatores linguísticos.

Demarcar as fronteiras geográficas da variação linguística, por outro lado, é eminentemente um padrão mensurável pela Dialetologia. A variação geográfica (diatópica) pode ser observada de maneiras diversas ou ainda ter o léxico como objeto de análise ${ }^{3}$. Observam-se designações diferentes em vários pontos do país para um mesmo objeto / coisa / fruta / ação / sentimento / seres / lugares. Isso faz com que sejam socialmente percebidas características regionais, as quais são graduais e nem sempre coincidem com as fronteiras geográficas; no entanto, as atitudes linguísticas não são delimitadas apenas por fronteiras geográficas, mas também, por fronteiras sociais.

De acordo com Cardoso (2010, p.26)

Apesar de "consideradas até certo ponto sinônimas", dialetologia e sociolinguística, ao se ocuparem da diversidade de usos da língua, atribuem um caráter particular e

\footnotetext{
${ }^{3}$ A dialetologia também observa outros níveis de análise da língua, como o fonético-fonológico ou o morfossintático, os quais não são alvo deste trabalho.
} 
individualizante no tratamento do seu objeto de estudo. [...] A dialetologia, nada obstante considerar fatores sociais como elementos relevantes na coleta e tratamento de dados, tem como base da sua descrição a localização espacial dos fatos considerados, configura-se, dessa forma, como eminentemente diatópica. A sociolinguística, ainda que estabeleça a intercomparação entre dados diferenciados do ponto de vista espacial, centra-se na correlação entre os fatos linguísticos e os fatores sociais, priorizando, dessa forma, as relações sociolinguísticas.

A Dialetologia Pluridimensional inclina seus estudos sobre os usos que os grupos de determinada região fazem da língua, estuda os traços linguísticos, por exemplo, vinculando-os aos aspectos sociais controlados na amostra. Essa ciência propõe-se a investigar dentro do sistema linguístico não só os aspectos variáveis de acordo com a diatopia e, por isso mesmo, Cardoso (2010, p. 26) menciona que "a Dialetologia tem, assim, duas diretrizes, dois caminhos, no exame do fenômeno linguístico, que se identificam nos estudos dialetais: a perspectiva diatópica e o enfoque sociolinguístico". Está aqui a interface.

E diante de toda a dinamicidade evidenciada da língua, através de léxico, podem-se verificar marcas regionais bastante afastadas entre si, sendo isso proveniente ou das grandes extensões territoriais ou dos hábitos linguísticos das comunidades e que, só podem ser verificadas pela Dialetologia.

Diversas ciências juntas, explicam fenômeno da variação. Procuram dar conta através dos postulados teóricos e da metodologia de trabalho daquilo que durante anos ficou esquecido aos olhos da ciência, afinal "[...] o linguista que entra no mundo só pode concluir que o ser humano é herdeiro legítimo da estrutura incrivelmente complexa que nós agora estamos tentando analisar e compreender." (LABOV, [1972] 2008, p. 18).

\section{Bola de Gude}

A gude é uma bola que pode ser de vidro maciço (material utilizado para sua confecção mais utilizado ultimamente), pedra ou metal (adaptada). Já foram empregados para confeccioná-la materiais como madeira, mármore, argila e cerâmica. Apesar de geralmente pequena, tem tamanhos variados. Podendo apresentar características translúcida, manchada ou intensamente colorida, ela é usada em jogo infantil que recebe a nomeação também de GUDE.

A brincadeira gude chegou ao Brasil trazida pelos colonizadores portugueses, juntamente com a bola de vidro de mesmo nome. A origem do nome gude vem de gode, do provençal, que significa "pedrinha redonda e lisa".

Uma das formas de jogar ou brincar com gude, por exemplo, consiste em utilizar um círculo desenhado no chão (aqui pode ser chão de pedra ou cimento, desenhado com giz), em que os jogadores devem colocar suas bolinhas, realizar o sorteio de quem começa a brincadeira e, seguindo essa ordem, pegar sua bolinha e com um impulso do polegar, acertar as bolinhas dos adversários; se conseguirem retirá-las do círculo, elas se tornam suas. Os jogadores seguintes devem tentar o mesmo acerto. Vence aquele que ficar com mais bolinhas de seus companheiros.

Em outras modalidades, faz-se uma cova ou buraco no chão, bem comum nas brincadeiras onde se tem chão de terra. Independentemente, das modalidades ou variantes do jogo, os objetivos não 
mudam muito, apesar de haver diversas formas/regras de jogar: impulsionando o polegar, atira-se uma bolinha tentando acertar as bolinhas dos adversários que estejam no círculo, no triângulo, tomando-as para si ou ainda, atingindo um alvo marcado previamente, como o buraco.

Realizou-se uma breve pesquisa lexicográfica objetivando identificar como o brinquedo está registrado em dicionários de língua portuguesa contemporâneos. A forma gude está registrada como verbete nos três dicionários pesquisados e a pesquisa lexicográfica que segue reforça a explicação do agrupamento realizado. Gude está descrita em Houaiss (2009, p. 999) como "jogo infantil com bolinhas de vidro que, num percurso de ida e volta, devem entrar em três buracos dispostos em linha reta, saindo vencedora a criança que chegar primeiro ao buraco inicial", "qualquer outro jogo infantil com bolinhas de vidro", ou a própria bolinha usada nesse jogo. No verbete, o autor traz também outras 11 variantes: belindre, berlinde, biloca, bilosca, birosca, bolita, búruca, búrica, peteca, pirosca, ximbra.

Em Ferreira (2010, p. 1064) encontra-se uma descrição semelhante à apresentada por Houaiss (2009): "1. Pedrinha redonda e lisa. 2. Jogo infantil em que se procura fazer entrar em três buracos bolinhas de vidro, ou os carocinhos pretos do fruto do saboeiro, ganhando o jogador que chegar primeiramente de volta ao primeiro buraco." Apresenta como variantes balela, bilosca, birosca, bolita, búraca, búrica, cabiçulinha, firo, peteca, pirosca, ximbra, berlinde e bute. Nesta acepção, todavia, há uma ausência de detalhes sobre as outras formas de jogar gude.

Ao realizar a pesquisa no dicionário Aulete (2012, p. 454), apreendeu-se que a lexia gude, está dicionarizada apresentando a definição: "jogo infantil que consiste em entrechocar bolinhas de vidro e encaixá-las em pequenos buracos ger. cavados na terra". Aulete (2012) apresenta também 15 variantes para esse termo, diferentes das expostas pelo Houaiss (2009), como por exemplo, baleba, bute, cabiçulinha, firo. Desprezam-se, aqui também, outras formas de brincar com gude, oferecendo uma forma mais genérica de descrever o jogo e o brinquedo.

A lexia bila não se encontra dicionarizada nem no Houaiss (2009) e nem no Aulete (2012), apesar de ter sido encontrada categoricamente na amostra do espaço pernambucano. Ao lançar o olhar na remissão das obras consultadas também não foi encontrado o termo dentre os apresentados. No entanto, Ferreira (2010, p. 314) cita-a como remissiva a gude.

\section{Comunidades ciganas em Silva (2017)}

Na pesquisa de Silva (2017), considerando-se as primeiras respostas de cada informante, através da análise dos dados, pode-se relatar que nenhuma lexia foi comum aos quatro municípios da pesquisa Miguel Calmon e Jacobina, na Bahia; Flores e Ouricuri, em Pernambuco. As lexias gude/grude estiveram presentes na Bahia, ao passo que bila foi categórica em Pernambuco.

Apenas na Bahia, um informante $(2,77 \%)$ - sexo feminino, $3^{\text {a }}$ faixa etária ${ }^{4}$ e alfabetizada - do total de 36 , não respondeu à questão. No total, depois de realizado o agrupamento ${ }^{5}$ das lexias, obtiveram-

\footnotetext{
4 Silva (2017), assim como Ribeiro (2012) utiliza a faixa etária como perfil para seleção dos informantes; no entanto, aquela considera a faixa (i) de 18 a 30 anos, (ii) de 31 a 49 anos e a (iii) de 50 a 65 anos; enquanto essa vale-se das faixas I e III.

5 Padrão de tratamento que busca apenas a variação lexical, por isso mesmo, neutraliza as variações fônicas, as lexias são agrupadas sem forma de flexão em gênero e/ou número, faz-se simplificação da derivação por grau e das lexias complexas em simples e definição do elemento aglutinador. Seguiu-se um critério para organização, baseado em Ribeiro (2012, p. 158-159).
} 
se apenas duas lexias diferentes para nomear o conceito apresentado na pesquisa - bila e gude -, o que representa variação restrita em relação a outras lexias do campo semântico de Jogos e brincadeiras do QSL, do ALiB, analisadas pelas pesquisadoras, a exemplo de cambalhota com doze variantes lexicais.

Mesmo não sendo o informante convidado sistematicamente a dar mais de uma resposta, apareceu, na Bahia, a lexia composta bolinha de gude, como segunda resposta - sem a inserção da consoante $\mathbf{r}$, o que denota uma possibilidade para uma variação de linguagem específica na forma da lexia simples (gude/grude), - já que a primeira realização do mesmo informante foi a lexia grude (informante do sexo masculino, faixa etária 2, com o ensino Fundamental I incompleto); e, em Flores - Pernambuco, foi documentada, na mesma situação, a lexia ximbrá ${ }^{6}$, num informante do sexo masculino, faixa etária 3, analfabeto.

A partir das respostas a questão 156 do QSL do ALiB, pode-se analisar a variação linguística sob o ponto de vista léxico-semântico e diatópico; no entanto, eles não oferecem possibilidades significativas para estudos da variação diastrática, diageracional e diassexual, uma vez que o resultado foi categórico por estado após o agrupamento realizado: gude (gude, grude, bolinha de gude) para Bahia e bila para Pernambuco. As lexias documentadas na amostra são definidoras das nomeações feitas sobre o brinquedo e foram agrupadas conforme critérios adotados em Ribeiro (2012), como explicitado na nota 5.

Os itens lexicais agrupados em gude ocorreram todos no mesmo espaço geográfico. No caso de bolinha de gude $(2,77 \%$ do total), optou-se pela redução da lexia composta no sintagma nominal - SN $=\mathrm{N}+\mathrm{SP}$ (prep. + N) - o núcleo do sintagma preposicionado passou a ser o "rótulo" porque tem a carga semântica mais significativa para o contexto. Este núcleo tornou-se o elemento aglutinador, uma vez que também ocorreu isoladamente, mostrando, assim, que carrega o mesmo significado. De bola para bolinha tem-se uma derivação; na pesquisa lexicográfica em uma das acepções de bolinha, Houaiss (2009) apresenta-a como "mesmo que bola de gude" e indica ser um regionalismo do Brasil. Os demais dicionários consultados - Ferreira (2010) e Aulete (2012) - não fazem referência ao termo no diminutivo com o valor de objeto do jogo.

As lexias gude, grude, bolinha de gude passam a ter o mesmo elemento aglutinador gude por ser essa a forma dicionarizada da lexia, também porque em grude o que se tem é uma variação fônica de gude, dada a inserção de um som na sílaba, transformando a sílaba simples em complexa, o que, por sinal, em termos hipotéticos, pode aqui, ser fruto de um traço cultural da comunidade verificados os $45,83 \%$ dessa produtividade, o que representa 11 dos 24 informantes baianos. Observando ainda o caso de grude, cinco informantes a utilizá-la são do sexo masculino e seis do feminino, o que não revela nenhuma hipótese dada a variável sexo; no entanto, ao observar a escolaridade, depara-se com 90,90\% de informantes analfabetos, alfabetizados e com estudos interrompidos no Ensino Fundamental I, revelando como uma possível proposição de associação à baixa escolaridade. Feito o agrupamento, gude passa a representar $100 \%$ das respostas válidas em território baiano.

No caso de bila, não houve qualquer variação fônica e o agrupamento recebeu a nomenclatura da própria lexia. Bila representou $100 \%$ das respostas válidas em Pernambuco.

Ao pesquisar sobre as lexias encontradas na amostra para se referir ao jogo/brinquedo questionado, reafirma-se que:

${ }^{6}$ Ximbra está registrada no Houaiss (2009) como um regionalismo de Alagoas e documentada também por Ribeiro (2012) nos pontos de pesquisa neste estado, representando $5,4 \%$ das lexias encontradas na sua pesquisa. 
(i) Bolinha de gude (a lexia composta) não é um verbete nas obras consulatadas. Ao transformar a lexia em simples verificou-se que o termo "bolinha" faz alusão a bola de gude, como também a gude referindo-se ao brinquedo citado anteriormente;

(ii) Bila não está sistematicamente dicionarizada; é forma remissa a gude em uma das obras consultadas (FERREIRA, 2010, p. 314);

(iii) A lexia grude é um verbete, no entanto a sua descrição não faz alusão à brincadeira ou ao brinquedo referido na questão 156 do QSL e sim, a uma espécie de cola utilizada para unir peças de materiais diversos;

(iv) Gude está dicionarizada e revela tanto o brinquedo como as modalidades de brincadeiras com a gude.

Realizados os agrupamentos com base na lexicografia, é apresentada e comentada a análise estatística: gude é um item lexical que representa $100 \%$ na produtividade da Bahia e bila $100 \%$, em Pernambuco.

Nos dois estados, as respostas válidas abrangem um valor absoluto de 35, apenas 01 informante (2,77\%) não respondeu à questão, assim, tem-se um total de 97,22\% das respostas demonstrando ser uma brincadeira do cotidiano das crianças bem conhecida, na área geográfica (BA e PE) e na comunidade cigana pesquisada.

Os dados expostos podem ser ratificados por meio da Figura 1, na qual a cor vermelha, representa gude, produtiva na Bahia, e a cor azul representa a lexia bila, categórica em Pernambuco. Mais uma vez, o fato de se ter um resultado contundente não permite muita discussão. É mister ressaltar que a análise aqui referida centra-se na primeira resposta do informante.

Figura 1: Carta 03 - Bolinha de gude

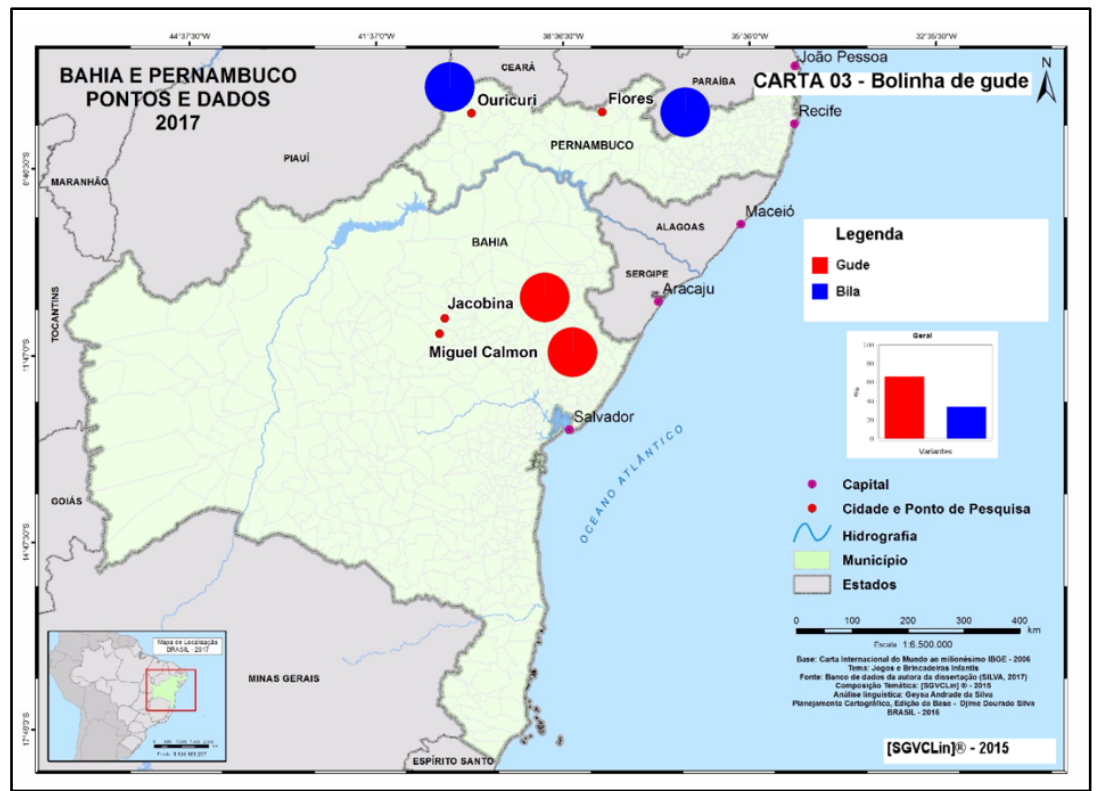


A pergunta 156 do QSL do ALiB, aqui retomada: "Como se chamam as coisinhas redondas de vidro com que os meninos gostam de brincar?" (COMITÊ NACIONAL..., 2001, p.34) faz uma referência direta ao brinquedo e não ao jogo, embora as obras lexicográficas pesquisadas abordem a acepção como o jogo, salvo o Houaiss (2009). A questão não apresentou problema de compreensão, contudo afirmar que "os meninos gostam de brincar" exclui naturalmente o gosto das meninas pela brincadeira, o que não é uma verdade e comprova-se quando se encontra a brincadeira em execução. Vencer essa concepção machista de olhar o brinquedo seria uma boa reformulação da questão, talvez o mais adequado seria trocar o termo "os meninos" por "as crianças".

\section{Comunidades não-ciganas em Ribeiro (2012)}

Para pesquisa de Ribeiro (2012), foram selecionadas 57 localidades pertencentes a 4 regiões geográficas brasileiras, totalizando 11 estados da Federação, o território coberto foi o do Falar Baiano e área de controle. Nesse espaço geográfico, foram encontradas $65,3 \%$ de ocorrência para lexia gude, a mais produtiva na área do Falar Baiano, e 4,1\% de bila, incluindo nos estados de Pernambuco e Piauí, e cidades baianas (Juazeiro e Barreiras). No estudo, Ribeiro (2012) depara-se com lexias bem produtivas para o brinquedo, precisamente, 41 formas lexicais diferentes (sem agrupamento). Todavia, para comparação com os dados da pesquisa de Silva (2017), isolaram-se as lexias presentes nas 22 localidades da Bahia e nos 4 pontos de Pernambuco.

Na Bahia, com 22 pontos de pesquisa, tem-se um total de 92 informantes entrevistados, 84 do interior e 8 da capital, com controle de faixa etária, sexo e escolaridade como prevê o Projeto ALiB. No Estado, Ribeiro (2012) obteve 98,91\% de respostas válidas, distribuídas em três agrupamentos lexicais e seus respectivos percentuais, dentre os quais $96,7 \%$ de produtividade para a lexia gude, conforme gráfico 1.

Gráfico 1: Gude na Bahia (RIBEIRO, 2012)

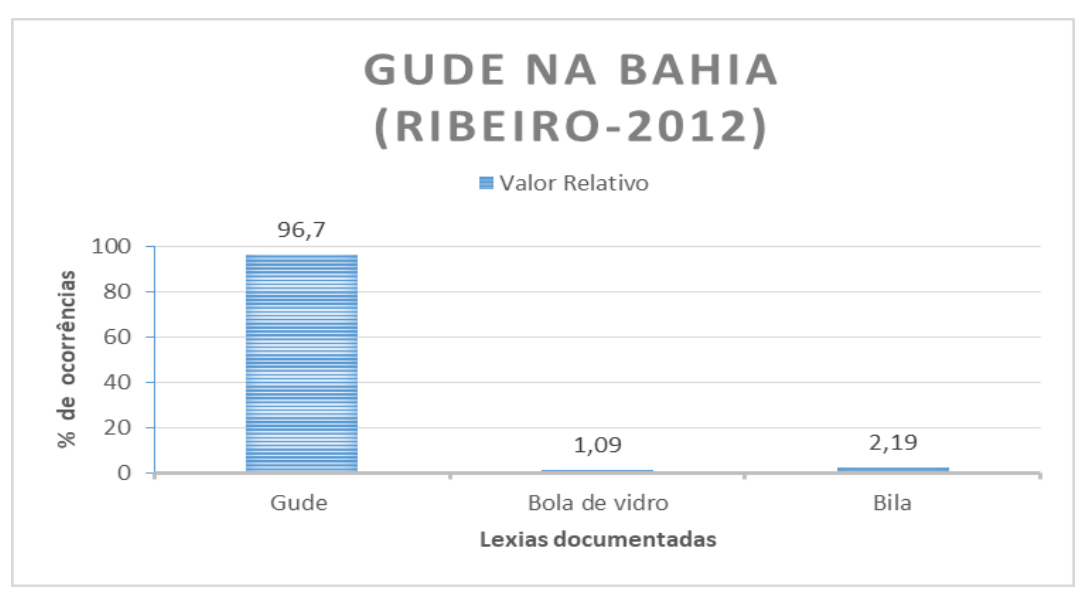

Fonte: Elaborado pelas autoras. 
Já na rede de pontos composta por 4 municípios do Estado de Pernambucano, a pesquisadora selecionou 4 informantes naturais de cada ponto no interior, totalizando 16 informantes e seguiu os mesmos pressupostos metodológicos descritos para a Bahia. A catalogação dos resultados revela um percentual de $100 \%$ de respostas válidas para a questão; embora, $56,25 \%$ seja de gude, há um alto percentual $(43,75 \%)$ de bila.

Gráfico 2: Gude em Pernambuco (RIBEIRO, 2012)

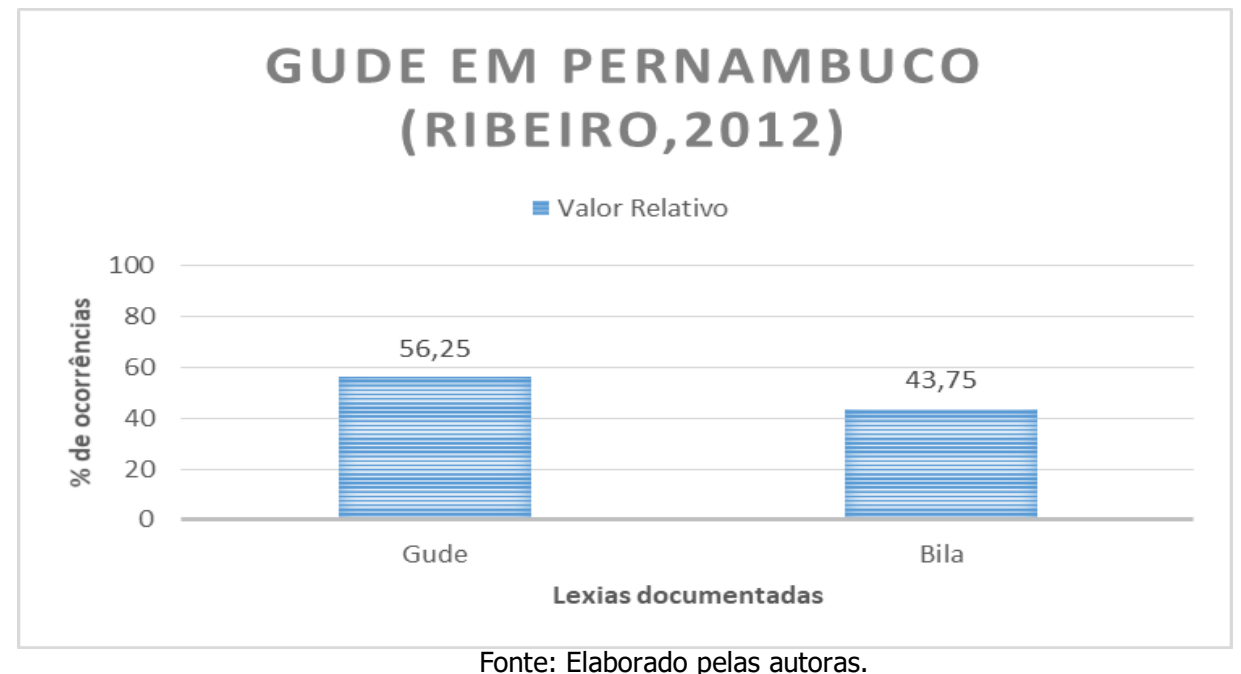

Ribeiro (2012) registra também a variante grude em Diamantina - MG e bolinha de grude em Jeremoabo - BA. As ocorrências foram agrupadas em gude, pela autora.

\section{A intercomparação dos estudos}

A tabela 1 apresenta dados que mostram que gude é a lexia de maior frequência na pesquisa de Silva (2017), com 100\% de produtividade na área baiana e, é também em Ribeiro (2012), com 96,7\% de produtividade, na Bahia. Em Pernambuco, enquanto na pesquisa de Silva (2017), bila foi a lexia mais produtiva categoricamente, Ribeiro (2012), obteve-se $56,25 \%$ de gude e $43,75 \%$ de bila.

Sem diversidade e em consonância com os dados obtidos, a Tabela 1 revela o teor quase categórico das respostas dos informantes pesquisados pelas autoras nas comunidades de etnias ciganas e não-ciganas.

A lexia bola de vidro apareceu na pesquisa de Ribeiro (2012), como primeira resposta, na fala de apenas um informante na cidade de Santana, na Bahia, ponto 92 do Projeto Atlas Linguístico do Brasil. A resposta reflete a fala de uma mulher da faixa etária II com 52 anos, dona de casa e com o Ensino Fundamental incompleto como grau de escolaridade. 
Tabela 1: Intercomparação da lexia gude entre Ribeiro (2012) e Silva (2017)

\begin{tabular}{|c|c|c|c|c|c|c|c|c|}
\hline \multirow[t]{2}{*}{ Lexia } & \multicolumn{2}{|c|}{$\begin{array}{c}\text { BAHIA } \\
\text { RIBEIRO }(2012)\end{array}$} & \multicolumn{2}{|c|}{$\begin{array}{c}\text { BAHIA } \\
\text { SILVA (2017) }\end{array}$} & \multicolumn{2}{|c|}{$\begin{array}{l}\text { PERNAMBUCO } \\
\text { RIBEIRO (2012) }\end{array}$} & \multicolumn{2}{|c|}{$\begin{array}{l}\text { PERNAMBUCO } \\
\text { SILVA (2017) }\end{array}$} \\
\hline & $\begin{array}{c}\text { Valor } \\
\text { absoluto }\end{array}$ & $\begin{array}{l}\text { Valor } \\
\text { relativo }\end{array}$ & $\begin{array}{c}\text { Valor } \\
\text { absoluto }\end{array}$ & $\begin{array}{l}\text { Valor } \\
\text { relativo }\end{array}$ & $\begin{array}{l}\text { Valor } \\
\text { absoluto }\end{array}$ & $\begin{array}{l}\text { Valor } \\
\text { relativo }\end{array}$ & $\begin{array}{c}\text { Valor } \\
\text { absoluto }\end{array}$ & $\begin{array}{l}\text { Valor } \\
\text { relativo }\end{array}$ \\
\hline Gude & 88 & $96,70 \%$ & 24 & $100 \%$ & 9 & $56,25 \%$ & - & - \\
\hline Bola de vidro & 1 & $1,09 \%$ & - & - & - & - & - & - \\
\hline Bila & 2 & $2,19 \%$ & - & - & 7 & $43,75 \%$ & 12 & $100 \%$ \\
\hline
\end{tabular}

\section{Considerações finais}

O léxico escolhido pelos ciganos das comunidades linguísticas selecionadas como resposta à pergunta número 156 do Questionário Semântico-Lexical na área semântico-lexical de Jogos e diversões infantis desta pesquisa revelou variantes lexicais fortemente marcadas pela variação diatópica. A intercomparação dos resultados obtidos nas comunidades ciganas pesquisadas com aqueles documentados nas pesquisas de Ribeiro (2012) assegura tal afirmação.

Retomando a pergunta motivadora do estudo, fornecem-se dados que marcam a variação lexical do povo cigano e não-cigano, pontuam-se também as seguintes reflexões de caráter conclusivo da intercomparação dos dados:

(i) $100 \%$ das localidades pesquisadas tiveram ocorrência de lexias para o brinquedo;

(ii) 97,22\% dos informantes apresentaram respostas válidas no estudo de Silva (2017) e, 98,91 no de Ribeiro (2012);

(iii) Gude e bila possuem amplitude geográfica semelhante nos estados em que ocorreram.

(iv) Na Bahia, gude é a lexia de maior frequência nas duas pesquisas.

(v) Em Pernambuco, na pesquisa com comunidades não-ciganas, tem-se gude com maior frequência; no entanto, nas comunidades ciganas ouvidas, bila ocupa esta posição.

(vi) A cartografia e os gráficos aqui apresentados permitem dar a visão diatópica do espaço geográfico estudado, em sua unidade (lexia e área homogênea) e sua diversidade (marcada pelas especificidades de cada estudo);

(vii) O léxico se mostra apropriado para confirmar a variação diatópica e, em um corpus mais amplo, possivelmente, áreas dialetais;

(viii) O fato de os ciganos terem uma infância mais curta, interrompida por volta dos dez anos de idade - fato da sócio-história da etnia - não interferiu na constituição do léxico do brinquedo em questão; alguns revelem conhecer o artefato, mas não terem brincado com ele. 
O estudo permitiu constatar que embora consideradas duas etnias distintas, não houve escolhas lexicais distintas para cada grupo étnico considerado, quando se observa a designação em foco para o brinquedo gude. $\mathrm{O}$ fato mais relevante da pesquisa comparativa foi a possibilidade de constatar que 0 determinante para as escolhas lexicais é o fator diatopia.

\section{Referências}

ANTUNES, I. O léxico de uma língua. In: Território das palavras: estudo do léxico em sala de aula. São Paulo: Parábola Editorial, 2012. p. 27-50.

AULETE, C. Dicionário escolar da língua portuguesa. Rio de Janeiro: Lexikon, 2012. p. 1072.

CALLOU, D. O atlas prévio dos falares baianos (APFB) e o estudo da variação linguística no Brasil. In: Estudos Linguísticos e Literários, n. 46, Salvador: Programa de Pós-Graduação em Língua e Cultura, Programa de Pósgraduação em Literatura e Cultura da Universidade Federal da Bahia, 13-31, jul./dez., 2012.

CARDOSO, S. Geolinguística: tradição e modernidade. São Paulo: Parábola, 2010.

COMITÊ NACIONAL DO PROJETO ALiB. Atlas Linguístico do Brasil: questionário 2001. Londrina: Ed. UEL, 2001. FERREIRA, A. B.H. Dicionário Aurélio da língua portuguesa. 5. ed. Curitiba: Positivo, 2010.

HALL, S. Identidade cultural na pós-modernidade. Tradução Tomaz Tadeu da Silva, Guaracira Lopes Louro. 11. ed., Rio de Janeiro: DP\&A, 2006.

HOUAISS, A; VILLAR, M. de S. Dicionário Houaiss da língua portuguesa. Elaborado pelo Instituto Houaiss de lexicografia e Banco de Dados da Língua Portuguesa S/C Ltda. Rio de Janeiro: Objetiva, 2009. 1986 p.

LABOV, W. [1972]. Padrões sociolinguísticos. Tradução de Marcos Bagno, Maria Marta Pereira Scherre, Caroline Rodrigues Cardoso. São Paulo: Parábola, 2008.

NUNES, J. H. Lexicologia e lexicografia. In: GUIMARÂES, E.; ZOPPI-FONTANA, M. (Org.). Introdução às ciências da linguagem - A palavra e a frase. 2. ed. Campinas, SP: Pontes Editores, 2010. p. 149-172.

OLIVEIRA, Ana Maria Pinto Pires; ISQUERDO, Aparecida Negri (Org.). As ciências do léxico: lexicologia, lexicografia, terminologia. 2. ed. Campo Grande: Ed. UFMS, 2001.

RIBEIRO, S. S. C. Brinquedo e brincadeiras infantis na área do falar baiano. v. 1, 2 e 3. 2012.793 f. Tese (Doutorado do Programa de Pós-Graduação em Letras e Linguística) - Instituto de Letras, Universidade Federal da Bahia, Salvador, 2012.

SILVA, G. A. da. Comunidades ciganas da Bahia e de Pernambuco: léxico, cultura e sociedade. 2017. 184 f. Dissertação (Mestrado do Programa de Pós Graduação em Estudos Linguísticos) - Departamento de Letras, Universidade Estadual de Feira de Santana, Feira de Santana, 2017.

SOUSA SANTOS, B. de. Modernidade, identidade e cultura de fronteira. In: social e o político na Pós-Modernidade. 8. ed. São Paulo: Cortez, 2000. p. 119-140. Pela mão de Alice: 0 